\title{
De Cidade Maravilhosa à cidade mercadoria: o Rio de Janeiro como valor de troca
}

From wonderful city to merchandise city: Rio de Janeiro as an exchange value

\section{Ana Carolina Brandão Vazquez*}

\begin{abstract}
Resumo - Este artigo tem como objetivo fomentar o debate acerca da reprodução das relações de produção capitalistas e seus impactos na produção social do espaço. Focaliza, em especial, os processos de reordenamento urbano promovidos na cidade do Rio de Janeiro a partir da gestão do Prefeito Eduardo Paes, com vistas a adequar a cidade para a recepção dos grandes eventos esportivos. Para tanto, valemo-nos do método materialista-dialético de análise, utilizando, principalmente, as contribuições do pensamento de Henri Lefebvre. O resgate do pensamento lefebvriano acerca do espaço e seus usos se justifica ainda na contemporaneidade, especialmente em tempos de capital financeirizado, que permite que a fragmentação do espaço subordine cada vez mais seu valor de uso ao valor de troca.

Palavras-Chave: reordenamento urbano; capital financeiro; direito à cidade; planejamento estratégico.
\end{abstract}

Abstract - This article aims to promote the debate about the reproduction of capitalist production relations and their impacts on the social production of space. It focuses, in particular, on the processes of urban reorganization promoted in the city of Rio de Janeiro by Mayor Eduardo Paes, with a view to adjusting the city for the reception of major sporting events. For this, we make use of the the materialistic-dialectical method of analysis, using mainly the contributions of Henri Lefebvre. The recourse to Lefebvre's ideas on space and its uses is still justified in contemporary times, especially in times of financialized capital, which allows the fragmentation of space to subordinate its use value more and more to the value of exchange.

Keywords: urban redevelopment, financial capital, right to the city, strategic planning.

\footnotetext{
* Assistente social. Doutoranda em Serviço Social pelo Programa de Pós-Graduação em Serviço Social da Universidade Federal do Rio de Janeiro. Correspondência: Rua Conde de Bonfim, 1136/202, Tijuca - Rio de Janeiro - RJ. CEP: 20530-003. Email: <acbvazquez@gmail.com>.
} 


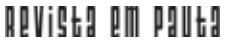

\} DE CIDADE MARAVILHOSA À CIDADE MERCADORIA - VAZQUEZ, A. C. B. \}

DOI $10.12957 /$ REP.2017.30384

\section{Introdução}

Desde que foi anunciado que o Rio de Janeiro seria cidade-sede da Copa do Mundo de 2014 e dos Jogos Olímpicos de 2016, muito se tem produzido acerca das intervenções urbanas promovidas pela prefeitura (em parceria com a iniciativa privada) nos espaços da cidade. Contudo, uma análise mais pormenorizada aponta que esse reordenamento urbano não se apresenta como uma novidade; ao contrário, está em curso, pelo menos, desde o início da década de 1990, a partir da gestão do prefeito César Maia, inspirado no "modelo Barcelona", como ficou conhecido o conjunto de transformações urbanísticas realizadas na capital catalã por conta dos Jogos Olímpicos de 1992.

É importante comentar que o conjunto de intervenções no espaço urbano na cidade de Barcelona, em preparação para sediar os Jogos Olímpicos de 1992, tornou-se um "modelo" para os especialistas em planejamento urbano. Na ânsia de integrar a cidade à esfera da globalização, esse modelo de gestão submete a cidade a uma lógica empresarial, a fim de torná-la competitiva para o mercado. Sendo assim, as cidades disputam entre si pelo investimento de capital, tornando-se flexíveis às suas exigências, em detrimento do seu uso social por parte de seus habitantes.

Desse modo, seguindo o rastro das análises de Vainer (2000), perguntamo-nos se, de fato, a preparação da cidade para receber esses megaeventos aconteceu em decorrência dos jogos em si, ou se, antes, a vinda dos jogos para o Rio de Janeiro foi uma consequência da maturação de um projeto de cidade que vem sendo gestado desde a década de 1990. O que um estudo mais profundo parece demonstrar é que o processo de reestruturação urbana, ocorrido mais intensamente a partir de 2009, na gestão do prefeito Eduardo Paes, passa ao largo de caracterizar-se como um processo surgido para adequar a metrópole à recepção de grandes eventos esportivos. Mas, sobretudo, trata-se de um projeto calcado na desapropriação de espaços urbanos centrais com o fim de criar novos fluxos de acumulação do capital, introduzindo uma política urbana orientada pela lógica neoliberal.

Deste modo, mais do que motivo das intervenções urbanas vivenciadas no Rio de Janeiro, os megaeventos caracterizaram-se como a possibilidade de realização de um projeto de cidade que há muito vem sendo pensado e concretizado.

\section{O processo de mundialização do capital e seus impactos na reconfiguração do espaço urbano}

Se, na contemporaneidade, a reconfiguração do espaço urbano tem no capital financeirizado a principal expressão do processo de acumulação capitalista, as transformações urbanas têm raízes mais profundas 
no capitalismo, tornando urbanização e produção um par dialético, configurando e reconfigurando a cidade de acordo com a necessidade do capital. Nesta direção, Harvey (2014, p. 30) argumenta que o surgimento das cidades modernas está diretamente atrelado à "concentração geográfica e social de um excedente de produção", sendo a urbanização um fenômeno de classe, haja vista que "os excedentes são extraídos de algum lugar ou de alguém, enquanto o controle sobre o uso desse lucro acumulado costuma permanecer nas mãos de poucos". Assim,

O capitalismo fundamenta-se, como nos diz Marx, na eterna busca da mais-valia (lucro). Contudo, para produzir mais-valia, as capitalistas têm que produzir excedentes de produção. Isso significa que o capitalismo está eternamente produzindo os excedentes de produção exigidos pela urbanização. A relação inversa também se aplica. O capitalismo precisa da urbanização para absorver o excedente de produção que nunca deixa de produzir. Dessa maneira, surge uma ligação íntima entre o desenvolvimento do capitalismo e a urbanização. (HARVEY, 2014, p. 30).

Essa "eterna busca por mais-valia", da qual nos fala Harvey (2014), tem no reinvestimento de parte dos excedentes de produção uma de suas bases, o que resulta numa expansão da produção de excedentes, implicando a criação de novos fluxos de escoamento. Quando esse escoamento é obstaculizado, defrontamo-nos com uma crise cíclica do capital. ${ }^{1}$

De acordo com Harvey (2014), é exatamente nos períodos de crise que a urbanização desempenha um papel ativo no que tange à absorção da produção excedente. Para exemplificar essa afirmação, o autor utiliza como exemplo a cidade de Paris no Segundo Império. Para ele, os projetos e construções operados por Haussman em 1853, em Paris, tinham como finalidade contribuir, por meio da urbanização, para a resolução dos problemas gerados pelo excedente de capital, convertendo-se em "um instrumento fundamental para a estabilização social" (HARVEY, 2014, p. 34).

No rastro dessas análises, Harvey (2014) intenta demonstrar que em todas as crises cíclicas do capital a urbanização desempenhou um papel crucial na garantia da expansão do capital. Entretanto, os processos urbanísticos assumiram novos contornos de acordo com o desenvolvimento das forças produtivas, apresentando, contemporaneamente, o mercado imobiliário como principal canal de escoamento "para parte significativa do excedente de capital" (HARVEY, 2014, p. 40).

O processo de mundialização do capital, vivenciado na atualidade, caracteriza-se como um "novo conjunto de relações internacionais e internas, que 'formam um sistema' e que modelam a vida social, não apenas no plano econômico, mas em todas as suas dimensões", reconfigurando o capita-

\footnotetext{
De acordo com Netto (2012), "[...] crises, não só as financeiras, fazem, também necessariamente, parte da dinâmica capitalista - não existe capitalismo sem crise. São próprias deste sistema as crises cíclicas [...] que se manifestam quando a acumulação capitalista se vê obstaculizada ou impedida".
} 


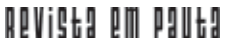

\} DE CIDADE MARAVILHOSA À CIDADE MERCADORIA - VAZQUEZ, A. C. B. \}

DOI 10.12957/REP.2017.30384

lismo mundial e os "mecanismos que comandam seu desempenho e sua regulação" (CHESNAIS, 1996, p. 13-14). Dessa forma, pressupõe uma nova configuração do espaço urbano, produzindo transformações que interferem diretamente na reorganização da metrópole como lócus privilegiado de reprodução do capital, orientando um novo processo de urbanização. Todavia, ao mesmo tempo em que potencializa a extensão do capital às esferas espaciais em escala exponencial, não elimina, mas agudiza as contradições socioespaciais. Assim, a mundialização do capital, sob a hegemonia do capital financeiro, se concretiza na cidade a partir do investimento no setor imobiliário.

A relação entre desenvolvimento capitalista e urbanização se agudiza em tempos de capital finaceirizado, propiciado pela ofensiva neoliberal, atingindo de forma profunda o acesso à cidade pela classe trabalhadora. Ainda segundo Harvey (2014, p. 70-71),

Desde meados da década de 1980, a política urbana neoliberal [...] concluiu que a redistribuição da riqueza a bairros, cidades e regiões menos favorecidas era inútil, e que, em vez disso, os recursos deveriam ser canalizados para os pólos de crescimento 'empresarial' mais dinâmicos. Uma versão espacial do efeito transbordamento se encarregaria então [...] de resolver todas essas desagradáveis desigualdades regionais, espaciais e urbanas. Entregar a cidade aos empreiteiros e aos especuladores financeiros redundaria no benefício de todos!

Tendo em vista que "a terra não é uma mercadoria no sentido corrente do termo, mas uma forma fictícia de capital que deriva das expectativas de aluguéis futuros" (HARVEY, 2014, p. 70), a especulação em torno dela tem propiciado um processo de gentrificação e valorização de acordo com a demanda do capital. A orientação das agências multilaterais, como o Banco Mundial, favorece o capital especulativo, atribuindo à desregulamentação do sistema financeiro a rápida expansão do financiamento imobiliário, em que o sistema de crédito desempenha papel fundamental.

O capital fictício ${ }^{2}$ tem, assim, estreita ligação com os mercados fundiários e imobiliários. Sob esta perspectiva, Harvey (2014, p. 89) atenta para o fato de que,

Quando bancos emprestam a outros bancos, ou quando o Banco Central empresta aos bancos que emprestam a especualdores imobiliários em busca de aluguéis adequados, o capital fictício parece cada vez mais uma regressão infinita de ficções construídas sobre ficções. O alavancamento a níveis cada vez mais altos (conceder empréstimos trinta vezes, e não três, a quantidade de depósito em espécie disponível) aumenta as

\footnotetext{
${ }^{2}$ No que diz respeito ao capital fictício, o autor se apoia nas formulações de Marx e o descreve como sendo "algo real, mas que é um fenômeno superficial que mascara alguma coisa importante das relações sociais subjacentes" (HARVEY, 2014, p. 88).
} 
quantidades fictícias de formação e fluxos de capital. E são esses fluxos que convertem os bens imóveis em algo irreal.

No que tange à cidade do Rio de Janeiro, que é nosso objeto de análise, os processos de urbanização sempre foram orientados segundo as demandas do capital, em detrimento das necessidades de uso da população, especialmente da população pobre. O processo de modernização da cidade do Rio de Janeiro, apesar de iniciado no fim do século XIX, se adensa consideravelmente na gestão municipal do prefeito Francisco Pereira Passos, nomeado diretamente pelo então presidente da República, Rodrigues Alves. O conjunto de intervenções no espaço urbano promovido por Pereira Passos tem como premissa a adequação da forma urbana "às necessidades reais de criação, concentração e acumulação do capital" (ABREU, 1997, p. 59), que incluíam uma sucessão de obras, indo desde os alargamentos de avenidas à desapropriação de casas e habitações das classes subalternas.

Segundo Abreu (1997), a Reforma Passos foi importante, principalmente, por representar como as novas formas de organização da vida social determinam novas funções à cidade. Além disso, caracterizou-se como "o primeiro exemplo de intervenção estatal maciça sobre o urbano, reorganizado agora sob novas bases econômicas e ideológicas, que não mais condiziam com a presença de pobres nas áreas mais valorizadas da cidade" (ABREU, 1997, p. 66).

$\mathrm{Na}$ atualidade, sob a égide do capital financeiro, vemos o acirramento dessas contradições com mais clareza: em contraposição à chamada integração da cidade aos processos da economia global, há uma deterioração das relações sociais no âmbito da vida cotidiana, com o enfraquecimento dos laços de pertencimento a uma rede comunitária, de vizinhança, de solidariedade. Isso se dá, em grande medida, em consequência da valorização do espaço enquanto valor de troca, em detrimento da sua realização enquanto valor de uso, que só pode ganhar sentido nas relações da vida cotidiana.

A ofensiva neoliberal ocorrida no Brasil nos anos de 1990 impacta sobremaneira as políticas urbanas, propiciando um novo tipo de planejamento, flexível e orientado pelo e para o mercado. Essa nova forma de gerir as cidades é chamada por Harvey (2005, p. 174) de empreendedorismo urbano e "se apóia na parceria público-privada, enfocando o investimento e o desenvolvimento econômico, por meio de construção especulativa do lugar em vez da melhoria das condições num território específico". Nesse sentido, o Estado cumpre um papel fundamental como instância necessária à criação das condições propícias à realização do reparcelamento e à valorização do solo segundo as demandas do capital.

A escolha da cidade do Rio de Janeiro para ilustrar as transformações contemporâneas do planejamento urbano de acordo com as demandas do capital não se dá de maneira aleatória. Sua importância nesse cenário se 


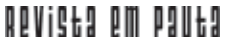

\} DE CIDADE MARAVILHOSA À CIDADE MERCADORIA - VAZQUEZ, A. C. B. \}

DOI 10.12957/REP.2017.30384

traduz em face do seu pioneirismo, haja vista ter sido a primeira cidade brasileira a aderir ao empreendedorismo urbano, através da formulação de um Plano Estratégico próprio, baseado em experiências internacionais. ${ }^{3}$

Experimentado pela primeira vez sob a gestão do prefeito César Maia (1993-1996), e em consonância com as agências multilaterais, o Plano Estratégico da cidade do Rio de Janeiro (PECRJ) segue a premissa da busca pelo desenvolvimento econômico e social articulado aos processos de globalização e mundialização, com vistas a transformar a cidade numa cidadeempresa ${ }^{4}$. Para tal, é necessário que exista uma administração eficiente, que possa "diagnosticar" (no sentido mais funcionalista do termo) quais são os pontos fracos e fortes da cidade, a fim de resolver os primeiros e potencializar os segundos, minimizando os "riscos" de investimento.

A elaboração do primeiro PECRJ se deu através da criação do Rio Sempre Rio, um consórcio de organizações público-privadas que teve como objetivo a formulação do plano. Cumpre enfatizar que, além da elaboração do PECRJ, e na esteira de suas formulações, a gestão do Prefeito César Maia foi marcada por intervenções importantes no reordenamento urbano da cidade, tendo como projetos mais proeminentes o Rio Cidade e o Favela-Bairro. ${ }^{5}$

Assim, o Plano Estratégico da cidade do Rio de Janeiro torna-se fonte fundamental para entendermos de que forma o Estado facilita e garante a remodelação do espaço urbano segundo as necessidades das relações de produção capitalistas. Sob a falácia do Estado mínimo, contida no discurso neoliberal, o que percebemos é uma intervenção direta do Estado nas políticas de planejamento urbano favoráveis ao desenvolvimento capitalista, sendo o Plano Estratégico um de seus mecanismos.

Desde 1993, com a formulação do primeiro Plano Estratégico para a cidade, outros planos, de outras gestões, foram elaborados, todos cumprindo a mesma premissa: aperfeiçoar o Rio de Janeiro enquanto cidade competitiva para o mercado mundial. Se há diferença entre eles, essas se caracterizam como pontuais, no sentido de atender de maneira mais satisfatória às tendências do mercado mundial, de acordo com as mudanças nas exigências atribuídas pelas agências de fomento internacionais.

O que nos chama atenção para fins deste artigo, todavia, são as permanências. Em todos eles vigora uma proposta "de abertura e extroversão econômicas propugnadas pelo receituário neoliberal. [...] o mercado constituído pela demanda de localizações pelo grande capital é o que qualifica a cidade como mercadoria" (VAINER, 2000, p. 80). O que per-

\footnotetext{
${ }^{3}$ Para Maricato (2015, p. 88-89), os Planos Estratégicos são ações inspiradas no Modelo Barcelona, que prometem "conduzir qualquer cidade ao pódio restrito das fashionable cidades globais. [...] Apesar da roupagem democrática e participativa, as propostas dos 'planos estratégicos' combinaram-se perfeitamente ao ideário neoliberal que orientou o ajuste das políticas econômicas nacionais, por meio do Consenso de Washington".

${ }^{4}$ Vainer (2009).

${ }^{5}$ Podemos inferir que os projetos Rio Cidade e Favela-Bairro foram os carros-chefes da gestão do prefeito César Maia, tendo impactos profundos sobre o planejamento urbano na cidade. Desse modo, merecem estudos aprofundados, o que foge ao escopo deste artigo.
} 
cebemos, portanto, é um processo de homogeneização da cidade, a fim de tornar a experiência do Modelo Barcelona universal, haja vista que as condições para sua efetivação devem ser a mesmas em todos os lugares.

Sob a influência do "modelo Barcelona", como já supracitado, o I PECRJ projetou um modelo de cidade que orientaria suas ações interventivas no espaço urbano de acordo com os interesses das grandes corporações internacionais. Essa tendência permanece nos planos posteriores, expressando um padrão de gestão urbana em consonância com a lógica neo-liberal. Desta feita, o planejamento estratégico consiste em deixar as cidades mais competitivas aos olhos do capital financeiro internacional, transformando-as em polos atrativos para o estabelecimento do capital transnacional.

A vitória da cidade do Rio de Janeiro como cidade-sede da Copa do Mundo de 2014 e dos Jogos Olímpicos de 2016 propicia o terreno fértil para o aprofundamento das estratégias de empreendedorismo urbano iniciadas nos anos de 1990 (HARVEY, 2005). Com a ascensão de Eduardo Paes à Prefeitura do Rio de Janeiro, em 2009, o processo homogeneizador identificado nos planos estratégicos, não só para a cidade do Rio de Janeiro, mas como mecanismo fundamental para a construção de uma cidade competitiva ao redor do mundo, pode ser claramente flagrado.

Comandada pela Secretaria de Ordem Pública, a Operação Choque de Ordem combinava ações, como a repressão ao trabalho informal de camelôs, o recolhimento da população em situação de rua, a internação compulsória de usuários de drogas, em especial o crack, a demolição de imóveis "irregulares", a construção de "eco limites", com o intuito de impedir o crescimento das favelas, etc. Segundo Eduardo Paes, essas intervenções no espaço urbano aconteceriam em prol de um "restabelecimento da autoridade municipal e de um cuidado com a cidade". ${ }^{6}$ Sob este discurso começam a ser erigidas as condições para obtenção de um consenso em torno desse projeto de cidade. Desse modo, esvazia-se seu sentido político e enaltece-se a importância da coesão e da solidariedade entre os diferentes segmentos da população carioca em prol do "bem-estar" da cidade", a fim de torná-la um polo de desenvolvimento, trazendo o progresso e benefícios para seus habitantes.

A necessidade do consenso torna-se, portanto, condição indispensável para a instauração do modelo de cidade competitiva. "Sem consenso não há qualquer possibilidade de estratégias vitoriosas. O plano estratégico supõe, exige, depende que a cidade esteja unificada, toda, sem brechas, em torno do projeto" (VAINER, 2000, p. 91).

\footnotetext{
${ }^{6}$ Fala do prefeito Eduardo Paes em entrevista concedida ao RJTV 1a edição em 6 de abril de 2009. http:// globotv.globo.com/rede-globo/rjtv-1a-edicao/v/eduardo-paes-fala-das-operacoes-choque-de-ordem/996243/

${ }_{7}^{7}$ Segundo Vainer (2009), é necessária a instauração da cidade como um sujeito coletivo, no imaginário social, para, assim, criar as bases necessárias para a obtenção do consenso.
} 


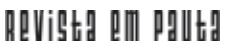

\} DE CIDADE MARAVILHOSA À CIDADE MERCADORIA - VAZQUEZ, A. C. B. \}

DOI $10.12957 /$ REP.2017.30384

Há, portanto, uma subordinação da política à gestão empresarial, com vistas a converter a cidade em uma mercadoria vendável, a fim de agradar um "mercado extremamente competitivo, onde outras cidades também estão à venda" (VAINER, 2000, p. 78). É preciso, assim, articular o plano local, no qual figuram as cidades, ao plano mundial, possibilitando a realização da reprodução social de acordo com a reprodução do capital.

Se, por um lado, essa forma de gerir a cidade traz grandes ganhos ao capital internacional, por outro interfere de forma nociva nas relações sociais e cotidianas estabelecidas pelos seus habitantes, em que pese, principalmente, a parcela empobrecida. Contraditoriamente, através do slogan da diversidade cultural, do respeito às diferenças locais e do desenvolvimento sustentável, o novo modelo de cidade proposto nos planos estratégicos "implica um processo de homogeneização e estabelecimento de padrões ideais de comportamento e modos de habitar a cidade" (CUNHA, 2013, p. 328). Deste modo, o processo homogeneizador imposto por esse modelo de gestão "eficiente" tende a promover

processos de gentrificação e transformação de bairros populares, muitas vezes identificados como bairros problemáticos e indesejáveis, em espaços enobrecidos e, consequentemente, inacessíveis à sua população de origem. Associados ao encarecimento do solo urbano e à especulação imobiliária, tais processos teriam tornado a cidade inacessível ao cidadão comum. (CUNHA, 2013, p. 328).

Como já mencionado, o remodelamento urbano, a partir das demandas do capital, não é uma novidade. A cidade do Rio de Janeiro, em particular, vivenciou inúmeros processos de intervenções urbanísticas a fim de se adaptar às exigências da sociedade burguesa. Ao longo do século XX, várias foram as gestões municipais que se encarregaram dessa tarefa. Entretanto, as medidas utilizadas de maneira mais aprofundada na gestão do prefeito Eduardo Paes, com vistas a mais um processo de reordenamento urbano, tornam-se emblemáticas, ao passo em que se sobrepõem à ordem democrática, aviltando direitos constitucionalmente garantidos.

O esforço, portanto, se traduz na necessidade de flagrar a ação do Estado no processo de conformação do espaço urbano e suas diferentes estratégias de intervenção, de acordo com as correlações de força presentes e a necessidade dessas medidas no processo de valorização do capital. A revitalização urbana, deste modo, faz parte de um projeto mais amplo que tende a expulsar os pobres dos centros (e zonas valorizadas) da cidade, em prol de "camadas restritas da sociedade" (SANTOS, 2012, p. 131). Nessa direção, é necessário aclarar o significado dessas ações dentro de um período de mundialização do capital e hegemonia do capital financeiro. 


\section{A atualidade da perspectiva marxista de análise da realidade concreta: contribuição do pensamento de Henri Lefebvre no que tange à produção social do espaço}

Partimos do pressuposto de que é no espaço da cidade que se realizam a hegemonia e a dominação da classe burguesa através do capital financeirizado, agudizando e tensionando as contradições quanto à sua função social, em contraposição à sua utilização como polo de especulação e valorização do capital. Analisar, portanto, a cidade como arena privilegiada da luta de classes torna-se fundamental para avaliarmos os processos de reordenamento urbano que vivenciamos na contemporaneidade. Nesse sentido, utilizando os pressupostos teóricos do pensamento de Henri Lefebvre, pretendemos lançar luz a esse modelo de cidade que vem sendo projetado na cidade do Rio de Janeiro.

Ao estudarmos o espaço como um elemento da realidade social, enxergamo-lo como parte da totalidade, sem a qual as relações sociais não se realizam, ou se realizam de forma parcial. Assim, entendemos o espaço como construído para atender às perspectivas de um dado modo de produção em uma determinada sociedade, dentro de um tempo histórico determinado, sendo, portanto, uma produção social.

Nesse sentido, o espaço torna-se "suporte de relações econômicas e sociais" (LEFEBVRE, 2006, p. 35), inserido que está no processo de reprodução da vida social. A organização e produção do espaço permitem a realização das relações sociais, sendo condição necessária para sua existência, haja vista que "elas se projetam em um espaço, elas se inscrevem nele, produzindo-o. Senão, elas permanecem na abstração 'pura'" (LEFEBVRE, 2006, p. 38). Sob este ângulo, procuraremos flagrar a construção do espaço dentro do modo de produção capitalista.

Centramos, assim, nossa discussão na importância do espaço para a reprodução das relações sociais de produção capitalista, ao mesmo tempo em que se transforma em potência revolucionária e de resistência: espaço de contradição. Para explicarmos, portanto, a centralidade do espaço nos termos supracitados, recorremos, mais uma vez, à tradição marxista, que tem em Henri Lefebvre, no que tange à teoria da produção social do espaço, seu principal expoente.

Nesse sentido, pensamos o espaço não encerrado nele mesmo, nem como simples modificação da natureza pelo homem, mas como produto das necessidades do capital, fator fundante e fundamental no que se refere ao direito à cidade. Essa tarefa se faz necessária, ainda na contemporaneidade, haja vista a submissão do espaço à lógica do mercado, mas também pela sua potencialidade criadora e transformadora. Assim, "a análise se refere ao conjunto de atividades prático-sociais, na medida em que elas se imbricam num espaço complexo, urbano e cotidiano, assegurando até certo ponto a reprodução das relações de produção (relações sociais)" (LEFEBVRE, 2008, p. 18). 


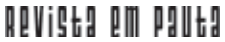

\} DE CIDADE MARAVILHOSA À CIDADE MERCADORIA - VAZQUEZ, A. C. B. \}

DOI $10.12957 /$ REP.2017.30384

Como enfatiza Lefebvre (2008), não há uma ligação transparente, facilmente apreendida, entre relações de produção e produção do espaço. Isso acontece porque o espaço, na sociedade capitalista, aparece fetichizado, reificado, não se revelando nas suas relações sociais. Desse modo, através da teoria da produção social do espaço, o autor busca desmistificar essa relação. A teoria da produção social do espaço, portanto, é um recurso metodológico que visa reconstruir as determinações da realidade, uma vez que essas relações e determinações entre espaço e modo de produção não são evidentes. Sob esse viés, pretende-se "não apenas caracterizar o espaço em que vivemos e sua gênese, mas reencontrá-la através do e pelo espaço produzido na sociedade atual" (LEFEBVRE, 2006, p. 47 - grifos nossos).

Vale mencionar que Lefebvre entende a esfera da produção capitalista como algo amplo, não apenas circunscrito ao âmbito da produção de coisas/produtos strictu sensu, mas também ideológico. Nesta perspectiva, o processo de reprodução ganha outro relevo: o de re-produção. A alteração morfológica da palavra não se dá por acaso. Podemos inferir, assim, que, com o emprego do hífen, Lefebvre busca enfatizar o novo sentido sintático dado por ele a esse termo: não se trata apenas da repetição das relações de produção capitalistas; não se refere apenas à esfera da reprodução biológica e de subsistência; não compete apenas à reprodução da força de trabalho. A re-produção das relações de produção as engloba mas, ao mesmo tempo, as transcende.

Nosso estudo parte da premissa de que o espaço não é meramente epistemológico, puro; é tampouco um instrumento, uma mediação; não é, ainda, simples reprodução da força de trabalho: ao contrário, o espaço é "uma modalidade da produção numa sociedade, no seio da qual contradições e conflitos se manifestam" (LEFEBVRE, 2008, p. 56). Ele é, portanto, não apenas um produto, mas um processo das relações de produção, um movimento dialético, gerador de contradições. É um conjunto de representações que não só o expressam, mas também o produzem.

Contudo, inserido na lógica das relações de produção capitalistas, o espaço não escapa à sua fragmentação e parcelamento enquanto propriedade privada do solo. Torna-se, portanto, espaço abstrato. Ou seja, é o espaço da homogeneização das práticas sociais, espaço das relações capitalistas de produção, fragmentado pela lógica capitalista da mercadoria, fracionado até o ponto de se tornar valor.

O espaço abstrato, portanto, é o espaço da burocracia, da racionalidade e de saberes instrumentais, o espaço mais adequado ao desenvolvimento capitalista, construindo-se a partir da violência, onde predomina a reprodução das relações de produção, com a inserção das ferramentas, da subjugação do valor de uso ao valor de troca, da fragmentação do espaço absoluto (espaço natureza), espaço das trocas de mercadorias. Cria-se, assim, um aspecto de homogeneidade que ratifica as diferenças, ao mesmo tempo em que tenta negá-las. 


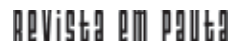

\} DE CIDADE MARAVILHOSA À CIDADE MERCADORIA - VAZQUEZ, A. C. B. \}

DOI 10.12957/REP.2017.30384

Esse espaço que se quer homogeneizado é o espaço da segregação, da autossegregação (no que diz respeito às classes dominantes, encasteladas em seus condomínios fechados, convivendo somente entre iguais), mas também de uma segregação imposta, construída no exercício da dominação, da organização da vida cotidiana. Nas palavras de Lefebvre (2012, p. 243), "curioso espaço: homogêneo e composto de guetos". A homogeneização, portanto, implica uma fragmentação do espaço e a hierarquização de relações de poder dentro da experiência das práticas espaciais. Surge, assim, a exigência da vigilância, do controle, a fim de manter a todo custo essa homogeneidade.

Mais uma vez a intervenção do Estado torna-se condição sem a qual esse processo de homogeneização, de construção do espaço abstrato, não seria possível, parcelando o solo, tornando-o mercadoria, planejando urbanisticamente uma cidade que atenda às necessidades do modo de produção capitalista.

Desta maneira, a hierarquização organiza funcionalmente o espaço a partir de um planejamento apartado da vida cotidiana, em detrimento das suas necessidades de uso. Um planejamento baseado numa razão técnica qualificada, que busca sua legitimidade na ciência, nos saberes científicos, na ideologia. Essa hierarquização é planejada através do Estado por meio de políticas públicas, mas também se concretiza pelo próprio mercado imobiliário, fazendo surgir a cidade como espaço privilegiado da acumulação capitalista e, consequentemente, da apropriação privada dos territórios interessantes ao capital.

Todavia, dizer que "as cidades se põem, sobretudo, ao serviço do capital é apenas um discurso" (SANTOS, 2012, p. 122). Dessa maneira, vale destacar que, embora fundamental para o processo de re-produção das relações sociais de produção na sociedade capitalista, a produção do espaço não "permitiu sozinha a sobrevivência do capitalismo" (LEFEBVRE, 2006, p. 143). Ao contrário, o espaço, na mesma medida em que proporciona a reprodução das relações sociais de produção, engendra novas relações sociais. Portanto,

Lefebvre atribui a sobrevivência do capitalismo à extensão e ampliação das relações sociais inerentes ao modo de produção capitalista, pesquisadas por Marx, a todo espaço e toda a sociedade, considerando que não há somente reprodução das relações sociais já estabelecidas, mas também a produção de novas relações sociais. (MARTINS, 2014, p. 276).

Sob este registro, como já enfatizado, o espaço não é estático, mecânico, passivo. Ao mesmo tempo em que concentra as condições gerais para a produção e re-produção das relações capitalistas, também age como polo de resistência das classes subalternizadas, engendrando novas relações. Assim, o espaço abstrato também é o espaço da contradição, da negação, 


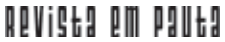

\} DE CIDADE MARAVILHOSA À CIDADE MERCADORIA - VAZQUEZ, A. C. B. \}

DOI 10.12957/REP.2017.30384

do conflito. É o espaço da resistência e da ocupação. A partir da saturação dessas contradições é possível transformar, através de uma práxis criadora e revolucionária, o espaço abstrato em espaço diferencial.

O espaço diferencial, na obra lefebvriana, diz respeito à dimensão utópica, ao momento de ruptura e superação da sociedade capitalista. É, necessariamente, heterogêneo o espaço do encontro e da centralidade do ser social. É uma potência. Entretanto, as condições para sua efetivação já estão dadas nas relações sociais contemporâneas, no espaço homogeneizador que é o espaço abstrato. Desse modo, o espaço diferencial só pode surgir através das contradições flagradas no espaço abstrato, religando o que o espaço abstrato separa.

Porém, como transformar esse espaço abstrato, homogêneo, uniforme e fetichizado em espaço diferencial, espaço do novo, das diferenças, da heterogeneidade? Há uma "construção social", uma "mudança de consciência" que faça com que haja essa transformação substancial da conformação do espaço? É possível, dentro da ordem burguesa, a passagem do espaço abstrato ao espaço diferencial?

A resposta a todas essas indagações é não! Para Lefebvre, ancorado na tradição marxista, apenas a luta de classes pode possibilitar a construção de um novo espaço. Apenas através da luta de classes é possível reivindicar o direito à diferença ${ }^{8}$, em detrimento do direito à propriedade.

A luta de classes? Ela intervém na produção do espaço, produção da qual as classes, as frações e grupos de classe são os agentes. A luta de classes, hoje mais do que nunca, se lê no espaço. Para dizer a verdade, só ela impede que o espaço abstrato se estenda ao planeta, literalmente apagando as diferenças; só a luta de classes tem uma capacidade diferencial, a de produzir diferenças que não sejam internas ao crescimento econômico considerado como estratégia, 'lógica' e 'sistema' (diferenças induzidas ou toleradas). As formas dessa luta são muito mais variadas que outrora. Dela fazem parte, certamente, as ações políticas das minorias. (LEFEBVRE, 2006, p. 52).

A luta de classes, assim, possibilita o acirramento das contradições, trazendo à tona as diferenças antes dissimuladas no espaço abstrato. Firma, portanto, a classe trabalhadora no seu lugar de potência transformadora, construindo, no interior desse espaço homogeneizado, espaços de resistência e luta.

Logo, em última análise, podemos inferir que a lógica capitalista mistifica as relações sociais, assim como a produção social do espaço. Este espaço, contudo, é sempre um campo em disputa, aberto à conformação e à transformação, repleto e movido pelas contradições, o que possibilita sua

\footnotetext{
8 "Direito de não ser classificado à força em categorias determinadas por potências homogeneizantes" (LEFEBVRE, 1973, p. 38).
} 
\} DE CIDADE MARAVILHOSA À CIDADE MERCADORIA - VAZQUEZ, A. C. B. \}

DOI 10.12957/REP.2017.30384

superação enquanto espaço abstrato para transformar-se em espaço diferencial.

\section{Considerações finais}

Como a construção do espaço não prescinde de uma carga histórica, o peso da formação social brasileira (periférica, tardia e dependente) incide nos usos que fazemos dela. Desta forma, podemos inferir que a maneira como se organizou o espaço urbano na cidade do Rio de Janeiro reflete a desigualdade social estruturante do nosso processo de formação: ganha relevo, assim, o mito da cidade partida. Aqui, cabe salientar que, se é verdadeira a afirmação de que existem duas realidades espaciais dentro da cidade, também é verdade que essas realidades se imbricam e se produzem dialeticamente; são complementares e não distintas.

Ao longo do século XX, a cidade do Rio de Janeiro foi palco de inúmeros projetos urbanísticos para atender às demandas crescentes do capital. Essas intervenções impactaram consideravelmente o espaço urbano e o uso que os habitantes fazem dele, em especial a população pobre. Desde o "bota abaixo" de Pereira Passos, as classes subalternas vêm sendo expulsas das áreas valorizadas pelos ciclos do capital, sendo cada vez mais remanejadas para as áreas periféricas. No entanto, as intervenções urbanas iniciadas na cidade a partir de 2009, em larga medida legitimadas pela vinda de grandes eventos esportivos para a cidade, como a Copa do Mundo de 2014 e os Jogos Olímpicos de 2016, reorganizaram o espaço urbano de maneira intensa e singular, conjugando não apenas obras vultuosas, mas também o realocamento de comunidades inteiras.

O que presenciamos hoje na cidade do Rio de Janeiro é a erupção de um modelo de cidade vendável e competitiva no mercado mundial. Ou seja, as intervenções urbanas que se processam na cidade do Rio de Janeiro na contemporaneidade se coadunam com as diretrizes das agências multilaterais, no que tange a um ordenamento do espaço nos moldes aceitáveis para torná-la competitiva no mercado mundial das cidades.

O discurso da crise urbana vem legitimar ações de remodelamento da cidade que impactam de maneira irreversível a vida de milhares de cidadãos cariocas, em especial aqueles que habitam áreas interessantes ao capital, o que impulsionou um processo de remoção de moradias sem precedentes na história da cidade. Em estimativa feita por Faulhaber e Azevedo (2015), cerca de 20.299 famílias (aproximadamente 67.000 pessoas) foram removidas de maneira compulsória do seu local de origem durante a gestão do prefeito Eduardo Paes.

Contudo, como nos diz Lefebvre (2008), o espaço deve ser analisado também nas suas temporalidades. O processo de urbanização da cidade do Rio de Janeiro projetou sobre esse espaço camadas e camadas de 


\section{ReVistg aाm paltg}

\} DE CIDADE MARAVILHOSA À CIDADE MERCADORIA - VAZQUEZ, A. C. B. \}

DOI 10.12957/REP.2017.30384

modos de vida e interação social, sedimentando sobre ele séculos de luta e resistência em prol da moradia popular, assim como a violência com a qual a classe trabalhadora foi sendo expulsa, por meio de inúmeras intervenções estatais, a fim de atender às necessidades da sociedade burguesa em expansão.

Espaço, portanto, acumulado, simultâneo, flagrante das expressões de dominação nos diferentes tempos históricos. A experiência da moradia configura-se como um registro histórico da produção social do espaço. O que as sucessivas intervenções no espaço urbano da cidade do Rio de Janeiro nos mostram é que, mesmo na produção capitalista do espaço, vamos encontrar uma transformação da sua tipologia, da sua forma/conteúdo, que se transforma e renova também na sua condição de valor, seguindo o fluxo das necessidades do capital. Assim, a produção do espaço vai agregando representações sociais que tornam o ato de habitar a cidade carregado de uma simbologia e de uma expressão material renovada. 
\} DE CIDADE MARAVILHOSA À CIDADE MERCADORIA - VAZQUEZ, A. C. B. \}

DOI 10.12957/REP.2017.30384

\section{Referências}

ABREU, M. de A. A evolução urbana do Rio de Janeiro. Rio de Janeiro: Iplanrio, 1997.

CHESNAIS, F. Mundialização do capital. São Paulo, Xamã, 1996.

CUNHA, N. V. da. O "modelo Barcelona" em questão: megaeventos e marketing urbano na construção da cidade-olímpica. O Social em Questão, ano XVI, n. 29, 2013.

FALHAUBER, L.; AZEVEDO, L. SMH 2016: remoções no Rio de Janeiro Olímpico. Rio de Janeiro: Mórula, 2015.

HARVEY, D. A produção capitalista do espaço. São Paulo: Annablume, 2005.

. Cidades rebeldes: do direito à cidade à revolução urbana. São Paulo: Martins Fontes, 2014.

LEFEBVRE, H. A produção do espaço. Paris: Éditions Anthropos, 2006. . Espaço e política. Belo Horizonte: Ed. UFMG, 2008.

. A Re-produção das relações de produção. Porto: Publicações Escorpião, 1973.

MARICATO, E. Para entender a crise urbana. São Paulo: Expressão Popular, 2015.

MARTINS, R. M. de. Entre o pensar e o viver: um estudo sobre a cidade como espaço estratégico da luta de classe. Dissertação (Mestrado) Universidade Federal do Rio de Janeiro, Escola de Serviço Social, Programa de Pós-Graduação em Serviço Social, 2014.

NETTO, J. P. Crise do capital e consequências societárias. Revista Serviço Social e Sociedade, São Paulo: Cortez, jul./set. 2012.

SANTOS, M. Por uma economia política da cidade: o caso de São Paulo. São Paulo: Editora da Universidade de São Paulo, 2012.

VAINER, C. Pátria, empresa e mercadoria: notas sobre a estratégia discursiva do Planejamento Estratégico Urbano. In: ARANTES, O.; VAINER, C.; MARICATO, E. A cidade do pensamento único: desmanchando consensos. Petrópolis: Vozes, 2000.

Recebido em 17 de abril de 2017.

Aprovado para publicação em 24 de maio de 2017.

DOI 10.12957/rep.2017.30384

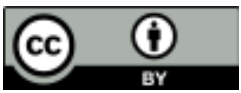

A Revista Em Pauta: Teoria Social e Realidade Contemporânea está licenciada com uma Licença Creative Commons Atribuição 4.0 Internacional. 